\title{
JOB DEMANDS-RESOURCES MODEL
}

\section{Its applicability to the workplace environment and human flourishing}

\author{
Michael Roskams*, Eileen McNeely, Dorota Weziak-Bialowolska, \\ and Piotr Bialowolski
}

\section{Background}

The job demands-resources (JD-R) model (see Figure 3.1; Demerouti, Bakker, Nachreiner, \& Schaufeli, 2001; Bakker \& Demerouti, 2014, 2017) is one of the most popular and influential models of work stress in the literature. The model can be summarised in a series of simple yet compelling propositions. All jobs share common characteristics that can be classified as 'demands' or 'resources', based on their effect on an employee. Demands instigate a health impairment process characterised by strain and exhaustion, eventually leading to burnout and other negative work outcomes. Resources stimulate work engagement, leading to higher motivation and other positive work outcomes. As such, the challenge for those tasked with job design is to minimise demands whilst maximising resources.

The JD-R model has become immensely popular in the two decades following its inception, inspiring hundreds of empirical articles and being used within thousands of organisations worldwide (Demerouti, Bakker, \& Xanthopoulou, 2019). As a result of its broadness and generalisability, it has been found to be equally applicable across a range of ostensibly diverse professional environments (Demerouti et al., 2019). The strength of the model lies in its ability to move beyond surface-level differences and identify the common characteristics that are universally associated with work outcomes.

The chapter is structured as follows. Firstly, the JD-R model is outlined in more detail. Secondly, a domain-specific extension of the JD-R model, termed the environmental demandsresources (ED-R) model, is presented and evaluated. Finally, the chapter concludes with a discussion of how the ED-R model ties in with theories of human flourishing and can be used to support a salutogenic (i.e., health-promoting) approach to well-being in the workplace.

\subsection{Outline of the JD-R model}

The JD-R Model assumes that every job shares common risks and opportunities for impaired or enhanced well-being and functioning. These characteristics can be divided into two broad categories: job demands and job resources.

*Corresponding author: mjroskams@googlemail.com 


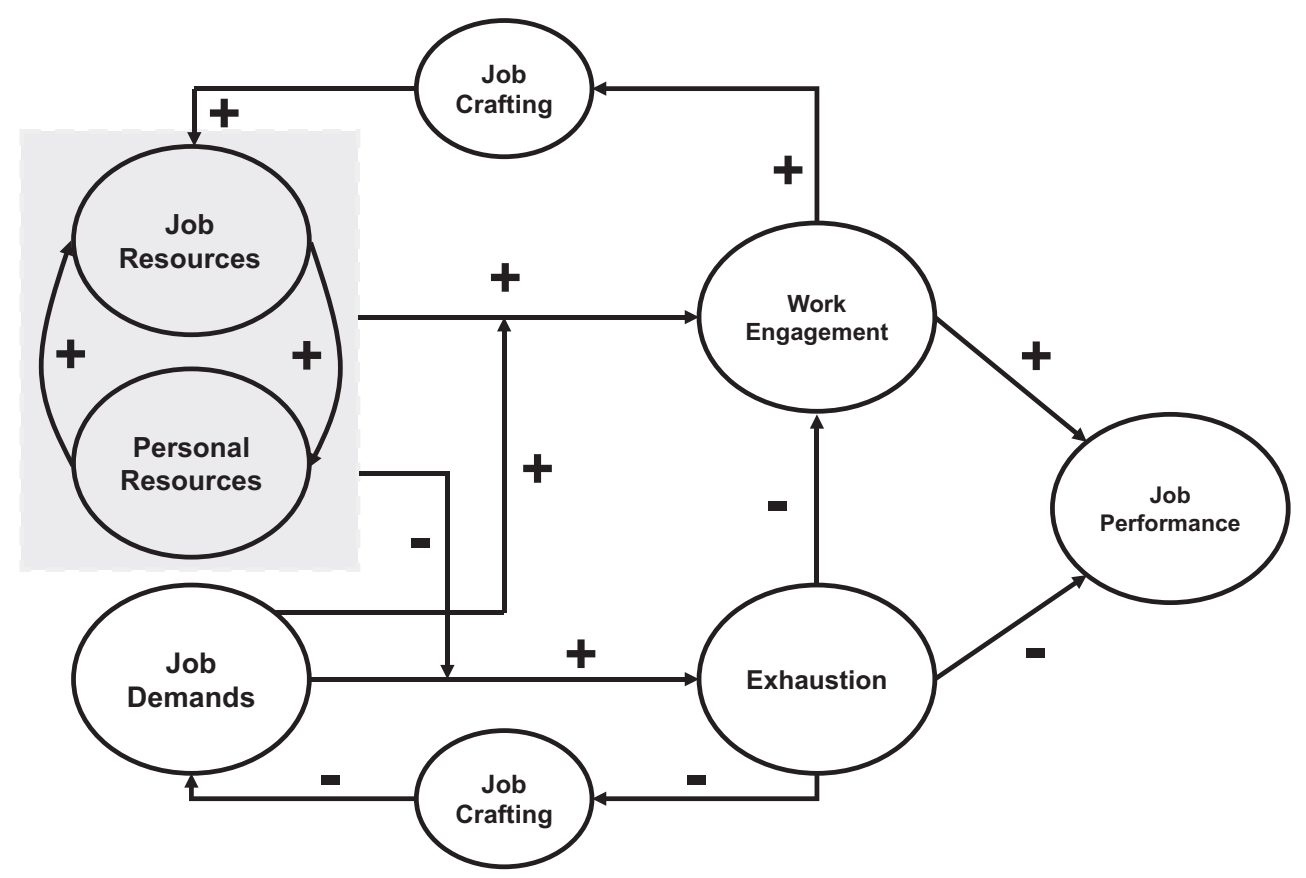

Figure 3.1 The job demands-resources model (Bakker \& Demerouti, 2014)

Job demands are defined as "those physical, social, or organizational aspects of the job that require sustained physical or mental effort and are therefore associated with certain physiological and psychological costs" (Demerouti et al., 2001, p. 501). Importantly, demands should be valued negatively by the employee (as opposed to difficult but positively valued challenges, which provide an opportunity to develop mastery and personal growth; Schaufeli \& Taris, 2014). Examples of such demands might include an irregular work schedule and demanding interactions with clients, amongst others.

Conversely, job resources are defined as "those physical, social, or organizational aspects of the job that may do any of the following: (a) be functional in achieving work goals; (b) reduce job demands and the associated physiological and psychological costs; (c) stimulate personal growth and development" (Demerouti et al., 2001, p. 501). Examples here could include organisational factors such as supervisor support and goal clarity, but they can also be widened to include personal resources such as resilience and interpersonal skills (Xanthopoulou, Bakker, Demerouti, \& Schaufeli, 2007).

Job demands and resources affect numerous work outcomes through two mediating pathways. First, the process of exhaustion is instigated by high demands and few resources. Chronic job demands require the employee to expend high levels of energy to achieve their work-related goals, with insufficient time for recovery. Eventually, this leads to a state of exhaustion. Similarly, a lack of job resources leads to a state of disengagement whereby the employee loses the motivation to expend effort to complete work. The combination of exhaustion and disengagement is symptomatic of burnout, which is in turn associated with various negative outcomes (e.g., absenteeism, impaired physical and mental health).

Whilst the absence of job resources causes demotivation, their presence can trigger a separate pathway termed work engagement. Job resources are intrinsically motivating because they satisfy 
fundamental human needs, thus engendering an engaged state of mind characterised by vigour (i.e., high levels of energy and mental resilience whilst working), dedication (i.e., a sense of significance, enthusiasm and challenge), and absorption (i.e., high levels of focus and feeling engrossed in one's work). In turn, work engagement is then associated with numerous positive outcomes (e.g., higher productivity, extra-role performance, positive affect at work).

Finally, the JD-R model also highlights the role of job crafting, which refers to proactive strategies taken by employees to alter the nature of their work (task crafting), their relationships with colleagues and clients (relationship crafting), and/or their appraisal of their work (cognitive crafting) (Wrzesniewski \& Dutton, 2001). When given the autonomy to do so, employees can thereby attempt to reduce perceived job demands and enhance job resources, thereby making the work more enjoyable and meaningful.

Altogether, the JD-R model has received good empirical support in the literature. Synthesising the large evidence base, different meta-analyses have confirmed the positive associations between job resources and work engagement (Christian, Garza, \& Slaughter, 2011; Crawford, LePine, \& Rich., 2010; Halbesleben, 2010) and between job demands and burnout (Alarcon, 2011; Crawford et al., 2010). Furthermore, research also supports the propositions that work engagement is positively associated with dedication and commitment (Halbesleben, 2010; Christian, Garza, \& Slaughter, 2011), whereas burnout is negatively related (Alarcon, 2011). A meta-analysis including only longitudinal research also supports the claims of the model (Lesener, Gusy, \& Wolter, 2019), providing more rigorous evidence to suggest that the concepts are causally related to one another, as opposed to being merely associated.

Overall, therefore, the JD-R model is a simple, yet effective, framework for representing the nature of work. In particular, it highlights three ways in which jobs can be adapted to improve employee well-being and productivity: (i) through the mitigation of job demands; (ii) through the enhancement of job resources; and (iii) through the facilitation of job crafting.

\section{Applicability to workplace studies}

Although the original conceptualisation of the JD-R model by Demerouti et al. (2001) acknowledges that an unfavourable physical work environment could be considered a job demand, the empirical JD-R literature has largely neglected the role of the physical environment as a potential source of job demands and resources (instead focusing on personal, social, and organisational factors). Correspondingly, the physical environment literature has tended to suffer from a lack of theory, where individual studies are typically segmented by discipline and unconnected to any conceptual framework (Ashkanasy, Ayoko, \& Jehn, 2014; Sander, Caza, \& Jordan, 2018; Weziak-Bialowolska, Dong, \& McNeely, 2018).

However, research from a variety of built environment disciplines (e.g., indoor environment quality, environmental psychology, corporate real estate, facilities management) clearly demonstrates that many aspects of the workplace environment have the same effects as other job demands and resources, and that many common behaviours within the workplace can be considered as examples of crafting. This can be presented separately as the ED-R model (see Figure 3.2).

\subsection{Environmental demands}

Environmental demands can be defined as aspects of the workplace environment that require an additional and sustained exertion of physical and/or mental effort, resulting in physiological and/or psychological strain. 


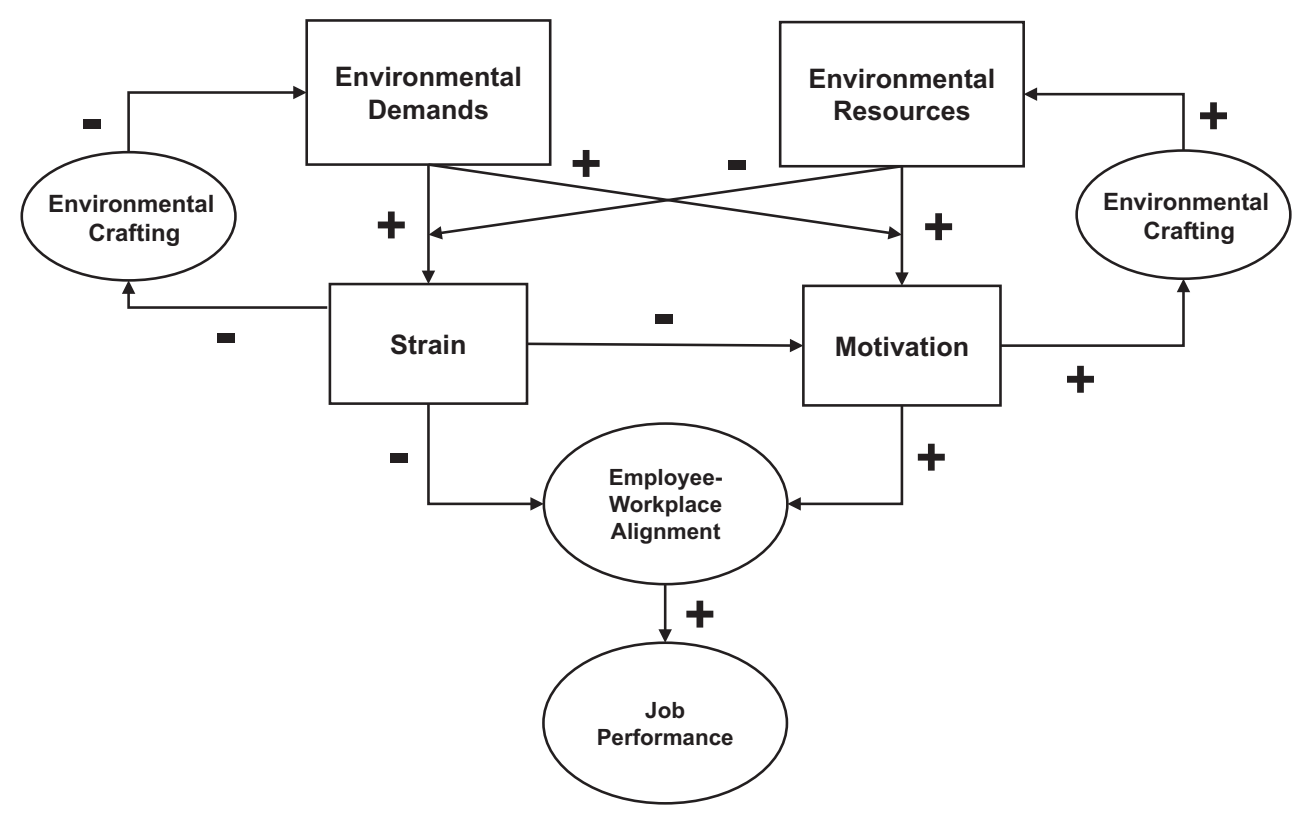

Figure 3.2 The environmental demands-resources model (Roskams \& Haynes, 2019)

For example, polluted indoor air can be considered an environmental demand, as it has a negative impact on cognitive performance (Allen et al., 2015; Satish et al., 2012, Zhang, Wargocki, Lian, \& Thyregod, 2016) and contributes to the development of 'sick building syndrome' symptoms, such as headaches, tiredness, and respiratory difficulties (Seppänen, Fisk, \& Mendell, 1999; Tsai, Lin, \& Chan, 2012). Other environmental factors which could deplete employees' energetic reserves might include uncomfortable temperatures (Rupp, Vásque, \& Lamberts, 2015; Wyon \& Wargocki, 2006), inadequate lighting (Boyce et al., 2006), and insufficient exposure to daylight (Jamrozik et al., 2019) (see also Chapter 13 The Theory of Attractive Quality).

Environmental demands may be particularly prevalent in modern open-plan offices, compared with traditional private offices. In shared workspaces, employees are frequently exposed to distraction by irrelevant background speech (Bodin Danielsson \& Bodin, 2009; Haapakangas, Hongisto, Eerola, \& Kuusisto, 2017; Mak \& Lui, 2012), leading to an estimated tenfold increase in acoustic complaints (Pejtersen, Allermann, Kristensen, \& Poulsen, 2006) and a doubling in the amount of time wasted due to noise (Kaarlela-Tuomaala, Helenius, Keskinen, \& Hongisto, 2009) relative to enclosed offices. Open-plan offices also increase perceptions of crowding and low privacy (Sundstrom, Burt, \& Kamp, 1980), leading to emotional exhaustion (Laurence, Fried, \& Slowik, 2013) and lower job satisfaction (Weziak-Bialowolska et al., 2018) amongst employees.

\subsection{Environmental resources}

Environmental resources can be defined as aspects of the workplace environment whose presence is associated with an enhanced ability to cope with demands and/or higher levels of work engagement.

For example, certain features of the workplace environment are effective in promoting recovery from stress. In particular, 'biophilic' design strategies (i.e., the integration of nature and natural analogues into the indoor built environment; see also Chapter 15 The Biophilia Hypothesis) have 
received significant research attention, building upon research that demonstrates that exposure to nature reduces psychological and physiological stress (Hartig, Mitchell, de Vries, \& Frumkin, 2014). When nature is brought into the office environment, most typically through interior plants, benefits include not only lower subjective stress but also higher health and job satisfaction, improved information processing and management, greater attention capacity, and higher self-rated productivity (Kaplan, 1993; Lohr, Pearson-Mims, \& Goodwin, 1996; Nieuwenhuis, Knight, Postmes, \& Haslam, 2014; Raanaas, Evensen, Rich, Sjøstrøm, \& Patil, 2011; Smith \& Pitt, 2009). In line with the definition that resources should be inherently engaging, biophilic design has also been observed to have an instorative effect (i.e., a positive impact on energy even in the absence of prior ego depletion; Beute \& De Kort, 2014).

The objects of workspace personalisation also serve as important environmental resources. Up to $90 \%$ of employees personalise the workspace with personally meaningful objects, such as photos of loved ones or artwork, if they have an opportunity to do so (Wells \& Thelen, 2002). This imbues the workplace with a sense of meaning (Brunia \& Hartjes-Gosselink, 2009) and helps to accelerate the development of personal identity in the workplace (Ashkanasy et al., 2014). In this way, the objects of personalisation act as visual stimuli which remind the employee of the deeper purpose of their work, which in turn helps to foster engagement and increased effort in the face of demands.

\subsection{Environmental crafting}

Finally, there is also good evidence to suggest that many behaviours within the workplace can be understood as examples of environmental crafting, in that they are directly motivated by a desire to improve one's working environment, through the mitigation of demands and/or the enhancement of resources.

For example, if they have the ability to do so, employees act in various ways to reduce discomfort in the workplace environment. In response to the demand of distracting background noise, it is common for employees to use headphones to improve acoustic comfort (Oseland \& Hodsman, 2018). In response to the demand of uncomfortable temperatures, employees might use personal fans or heaters to improve thermal comfort (Rupp et al., 2015). If the workplace environment is perceived as stale and corporate, then the act of personalisation is another example of environmental crafting, motivated by the desire to have easy access to resources at one's workspace.

Employees working in offices with flexible working arrangements often have an even greater ability to craft their working environment. By providing more freedom over where and when to work (referred to as spatial crafting and time crafting, respectively; Wessels et al., 2019), employees become better able to ensure that their working environment has few demands and abundant resources.

\subsection{Relationship to human flourishing}

Overall, the presence of demands and resources (relative to each individual's idiosyncratic needs and preferences) determines the level of 'alignment' between the employee and the workplace. In turn, more aligned workplaces will have a more positive impact on human flourishing (see also Chapter 14 Flourish Theory). As such, the ED-R model can be used to support a regenerative culture of well-being within organisations, in line with wider initiatives towards sustainable development goals (McNeely, 2018; Serafeim, Rischbeith, \& Koh, 2020; Wahl, 2016).

Essentially, flourishing can be understood as a state of fulfilment which arises when universal human needs are met. Specifically, the concept of human flourishing is conceptualised as a 
general construct with five distinct but interrelated components: life satisfaction and happiness; mental and physical health; meaning and purpose; character strengths; and close social relationships (VanderWeele, 2017; VanderWeele, McNeely, \& Koh, 2019). By systematically identifying and mitigating demands whilst enhancing resources, an environment more conducive to flourishing is provided.

Indeed, the ED-R model is congruent with more general frameworks for human flourishing within organisations. For example, the SHINE (Sustainability and Health Initiative for Net-Positive Enterprise) model (see Figure 3.3) developed at the Harvard T.H. Chan School of Public Health draws from a rich bank of literature in the social, psychological, management, and health sciences to identify key elements associated with human need fulfilment, resiliency, work performance, and engagement (Braunchli, Jenny, Fullemann, \& Bauer, 2015; Grossmeier et al., 2020; Jenny, Bauer, Vinje, Vogt, \& Torp, 2017; Kaufman, 2020; Medvedev \& Landhuis, 2018; Roskams \& Haynes, 2019, Weziak-Bialowolska, Bialowolski, Leon, Koosed, \& McNeely, 2020c). These key elements support flourishing precisely because they constitute specific resources or assets needed for employees to mitigate demands. The data thus far confirm the importance of these work arrangements for driving performance at work and overall flourishing in life and therein reaffirm the overall premise of the ED-R model (Bialowolski, McNeely, VanderWeele, \& Weziak-Bialowolska, 2020; Gale, Mordukhovich, Newlan, \& McNeely, 2019; Weziak-Bialowolska, Koosed, Leon, \& McNeely, 2017; Weziak-Bialowolska et al., 2018; WeziakBialowolska, McNeely, \& VanderWeele, 2019a; Weziak-Bialowolska, Bialowolski, \& McNeely, 2019c, 2020a; Weziak-Bialowolska, Bialowolski, Sacco, VanderWeele, \& McNeely, 2020b; Weziak-Bialowolska et al., 2020c).

Most importantly for this chapter, the SHINE model highlights the importance of physical working conditions as a key component of a regenerative work environment (alongside more general psychosocial job characteristics). In line with the salutogenic perspective and towards the overall aim of providing jobs which enhance rather than detract from well-being, the ED-R model can be used for the specific purpose of optimising the workplace environment.

\section{A Systems Approach to Well-being and Flourishing}

\begin{tabular}{|c|c|c|c|c|}
\hline \multicolumn{3}{|c|}{$\begin{array}{c}\text { REGENERATIVE } \\
\text { WORK ENVIRONMENTS }\end{array}$} & \multicolumn{2}{|c|}{ INDIVIDUAL FLOURISHING } \\
\hline & $\begin{array}{l}\text { CARING } \\
\text { CULTURE }\end{array}$ & & \multirow{2}{*}{\multicolumn{2}{|c|}{ Happiness \& life satisfaction }} \\
\hline $\begin{array}{l}\text { Access to Healthy } \\
\text { Nutrition }\end{array}$ & $\begin{array}{l}\text { Physical working } \\
\text { conditions }\end{array}$ & Recognition & \multirow[t]{2}{*}{ Happy } & \\
\hline Job Autonomy & $\begin{array}{l}\text { Manageable } \\
\text { Workload }\end{array}$ & $\begin{array}{l}\text { Supportive } \\
\text { Relationships }\end{array}$ & & Physical and mental health \\
\hline Job Security & Fair Wages & $\begin{array}{l}\text { Work/Life } \\
\text { Integration }\end{array}$ & Healthy & Meaning and purpose \\
\hline Zero Harassment & $\begin{array}{l}\text { Learning and } \\
\text { Growth }\end{array}$ & $\begin{array}{l}\text { Meaningful } \\
\text { Job }\end{array}$ & Engaged & Character strength \\
\hline
\end{tabular}

Figure 3.3 SHINE work and well-being model 


\section{Methodological/research approaches}

A variety of research methodologies can, and should, be used to empirically validate the propositions of the ED-R model. The model is in a nascent stage, and it will be necessary to confirm the assumed relationships between environmental demands and strain, between environmental resources and motivation, and between employee-workplace alignment and flourishing.

Firstly, recognising the fact that the majority of workplace environment research has focused largely on pathogenic factors, more research is needed to test the relationship between different environmental resources and different components of flourishing. The flourishing index (FI), which is embedded in the overarching SHINE model and has shown good psychometric properties (Weziak-Bialowolska et al., 2019a; Weziak-Bialowolska, McNeely, \& VanderWeele, 2019b), can be a suitable tool for this type of research. Using this framework, research(ers) would assess the ways in which a comprehensive, yet not exhaustive, set of different workplace demands and resources can affect general life satisfaction and happiness, mental and physical health, meaning and purpose, social connectedness, and character strengths of overall flourishing.

Secondly, researchers must resist the urge to restrict their inquiries solely to their own specialisms and instead to consider the entirety of environmental forces acting upon office occupants. A workplace intervention might successfully achieve a reduction in one environmental demand but inadvertently increase other demands and/or decrease resources, resulting in a worse working environment. The need to evaluate a comprehensive set of workplace factors across various work settings prompted the development of the SHINE model. To advance knowledge in the field, researchers should apply a consistent and broad set of workplace factors in longitudinal cohorts and use rigorous methods, such as pre-/post-intervention studies, ideally with a control group, to test assumptions of causality within the ED-R model. Further, qualitative techniques such as interviews and focus groups might be useful for identifying important demands or resources which have not yet been considered by the researchers.

Finally, to provide practitioners with more useful insight, it would be important to link employees' perceptions with objective assessments of environmental conditions. By comparing subjective and objective data, it would help confirm which conditions are associated with better or worse outcomes, such as work performance, engagement, and flourishing. The challenge for the aggregation of both subjective and objective information is that both environmental conditions and subjective perceptions are liable to momentary fluctuation, which can result in a lack of concordance or measurement accuracy of the intended condition or outcome. For example, the perception of poor air quality could be missed by employees completing a survey shortly after a momentary mechanical failure of the ventilation system. Instead, it may be more suitable to use either longitudinal survey data linked with continuous objective measurements of working conditions or repeated random experience sampling to assess employee-workplace interactions on a moment-by-moment basis (e.g., Roskams \& Haynes, 2020).

\section{Limitations}

The ED-R model shares the limitations of the JD-R model (e.g., Schaufeli \& Taris, 2014). Specifically, the generalisability of the model comes at the cost of limited specificity; no predictions are made within the ED-R model about the strength of the relationships between different demands, resources, and outcomes. It also remains unclear whether combinations of different demands and/or resources are additive or multiplicative in their effects. Hence, whilst 
the ED-R model can be viewed as a comprehensive meta-theory for the workplace environment, it would also be necessary to apply other frameworks, such as the SHINE model, to explain the numerous specific factors and relative relationships in the model with greater detail and predictive power.

\section{Theory relevance to practice}

This chapter explored the conditions for 'healthy work' by exploring the JD-R model in relation to the workplace environment and then examining how this approach aligns with the more general SHINE model for flourishing at work. Evidence-based approaches to workplace practice should be contextualised within these theoretical frameworks and explicitly guided towards connecting workplace resources directly to performance and overall flourishing.

Specifically, workplace practitioners can apply the ED-R model to practice by implementing top-down strategies such as identifying and mitigating environmental demands (e.g., monitoring and reducing airborne pollutants) and increasing the presence of environmental resources (e.g., using biophilic design within the office). This process can be supported by a typology of environmental demands and resources, derived from previous research (see Roskams \& Haynes, 2021). Practitioners should have a good understanding of the various environmental factors which may impact an employee's well-being and productivity and aim to ensure that the workplace is designed and maintained in such a way that it will continue to provide physical, functional, and psychological comfort for users.

However, it should also be recognised that significant inter-individual variability exists between different individuals and different types of work, and the strategies required to provide an optimal working environment may vary depending on these circumstances. Interventions delivered at the group level are likely to be welcomed by some employees but considered unhelpful by others. Hence, the top-down strategies should be complemented with bottom-up, user-directed strategies designed to facilitate the individual process of environmental crafting (e.g., implementing flexible workplace policies). This will allow the workplace users themselves to ensure that their working environment is free of demands and abundant in resources.

By applying these strategies, the hidden arrangements at work which give rise to both harms and benefits can be made visible. The approach presented in this chapter emphasises a holistic model of well-being in which work systems can be optimised to address specific human needs, such as social connectedness, or designed to affect multiple outcomes simultaneously. By uncorking the user experience of work in relation to their well-being, it becomes possible to gain new insights and opportunities to build a regenerative workplace that fits with the goals of sustainability and societal well-being.

\section{Further reading}

- Bakker, A. B., \& Demerouti, E. (2017). Job demands-resources theory: Taking stock and looking forward. Journal of Occupational Health Psychology, 22, 273-285. https://doi.org/10. 1037/ocp0000056

- Bodin Danielsson, C., Bodin, L., Wulff, C., \& Theorell, T. (2015). The relation between office type and workplace conflict: A gender and noise perspective. Journal of Environmental Psychology, 42, 161-171. https://doi.org/10.1016/j.jenvp.2015.04.004

- Khazanchi, S., Sprinkle, T. A., Masterson, S. S., \& Tong, N. (2018). A spatial model of work relationships: The relationship-building and relationship-straining of workspace design. Academy of Management Journal, 43(4), 590-609. https://doi.org/10.5465/amr.2016.0240 
- Roskams, M., \& Haynes, B. P. (2019). Salutogenic workplace design: A conceptual framework for supporting sense of coherence through environmental resources. Journal of Corporate Real Estate, 22(2), 139-153. https://doi.org/10.1108/JCRE-01-2019-0001

- Weziak-Bialowolska, D., Dong, Z., \& McNeely, E. (2018). Turning the mirror on the architects: A study of the open-plan office and work behaviors at an architectural company. Frontiers in Psychology, 9, 2178. https://doi.org/10.3389/fpsyg.2018.02178

\section{References}

Alarcon, G. M. (2011). A meta-analysis of burnout with job demands, resources, and attitudes. Journal of Vocational Behavior, 79, 549-562. https://doi.org/10.1016/j.jvb.2011.03.007

Allen, J., MacNaughton, P., Satish, U., Santanam, S., Vallarino, J., \& Spengler, J. (2015). Associations of cognitive function scores with carbon dioxide, ventilation, and volatile organic compound exposures in office workers: A controlled exposure study of green and conventional office environments. Environmental Health Perspectives, 124(6), 805-812. https://doi.org/10.1289/ehp.1510037

Ashkanasy, N., Ayoko, O., \& Jehn, K. (2014). Understanding the physical environment of work and employee behavior: An affective events perspective. Journal of Organizational Behavior, 35(8), 1169-1184. https://doi.org/10.1002/job.1973

Bakker, A. B., \& Demerouti, E. (2014). Job demands-resources theory. In C. Cooper \& P. Chen (Eds.), Wellbeing: A complete reference guide (pp. 37-64). Hoboken, NJ: Wiley-Blackwell.

Bakker, A. B., \& Demerouti, E. (2017). Job demands-resources theory: Taking stock and looking forward. Journal of Occupational Health Psychology, 22, 273-285. https://doi.org/10.1037/ocp0000056

Beute, F., \& de Kort, Y. (2014). Natural resistance: Exposure to nature and self-regulation, mood, and physiology after ego-depletion. Journal of Environmental Psychology, 40, 167-178. https://doi.org/10.1016/j. jenvp.2014.06.004

Bialowolski, P., McNeely, E., VanderWeele, T. J., Węziak-Białowolska, D. (2020). Ill health and distraction at work: Costs and drivers for productivity loss. PLoS One, 15(3), e0230562. https://doi.org/10.1371/ journal.pone. 0230562

Bodin Danielsson, C., \& Bodin, L. (2009). Difference in satisfaction with office environment among employees in different office types. Journal of Architectural and Planning Research, 26(3), 241-257. Retrieved from www.jstor.org/stable/43030872

Boyce, P., Veitch, J. A., Newsham, G. R., Jones, C. C., Heerwagen, J., Myer, M., \& Hunter, C. M. (2006). Lighting quality and office work: Two field simulation experiments. Lighting Research E Technology, 38(3), 191-223. https://doi.org/10.1191\%2F1365782806lrt161oa

Braunchli, R., Jenny, G., Fullemann, D., \& Bauer, G. (2015). Towards a job demands-resources health model: Empirical testing with generalizable indicators of job demands, job resources, and comprehensive health outcomes. Biomedical Research International, 959621. https://doi.org/10.1155/2015/959621

Brunia, S., \& Hartjes-Gosselink, A. (2009). Personalization in non-territorial offices: A study of a human need. Journal of Corporate Real Estate, 11(3), 169-182. https://doi.org/10.1108/14630010910985922

Christian, M. S., Garza, A. S., \& Slaughter, J. E. (2011). Work engagement: A quantitative review and test of its relations with task and contextual performance. Personnel Psychology, 64, 89-136. https://doi. org/10.1111/j.1744-6570.2010.01203.x

Crawford, E. R., LePine, J. A., \& Rich, B. L. (2010). Linking job demands and resources to employee engagement and burnout: A theoretical extension and meta-analytic test. Journal of Applied Psychology, 95, 834-848. https://doi.org/10.1037/a0019364

Demerouti, E., Bakker, A. B., Nachreiner, F., \& Schaufeli, W. B. (2001). The job demands-resources model of burnout. Journal of Applied Psychology, 86, 499-512. https://doi.org/10.1037/0021-9010.86.3.499

Demerouti, E., Bakker, A. B., \& Xanthopoulou, D. (2019). Job demands-resources theory and the role of individual cognitive and behavioral strategies. In T. Taris, M. Peeters, \& H. de Witte (Eds.), The fun and frustrations of modern working life: Contributions from an occupational health psychology perspective (pp. 94-104). Kalmthout, Belgium: Pelckmans Pro.

Gale, S., Mordukhovich, I., Newlan, S., \& McNeely, E. (2019). The impact of workplace harassment on health in a working cohort. Frontiers in Psychology, 10, 1181. https://doi.org/10.3389\%2Ffpsyg.2019.01181

Grossmeier, J., Castle, P., Pitts, J., Saringer, C., Jenkins, K. R., Imboden, M., . . \& Mason, S. (2020). Work place wellbeing factors that predict employee participation, health and medical cost impact, and perceived support. American Journal of Health Promotion, 34(4), 349-358. https://doi.org/10.1177/0890117119898613 


\section{Michael Roskams et al.}

Haapakangas, A., Hongisto, V., Eerola, M., \& Kuusisto, T. (2017). Distraction distance and perceived disturbance by noise: An analysis of 21 open-plan offices. The Journal of the Acoustical Society of America, 141(1), 127-136. https://doi.org/10.1121/1.4973690

Halbesleben, J. R. B. (2010). A meta-analysis of work engagement: Relationships with burnout, demands, resources, and consequences. In A. B. Bakker \& M. P. Leiter (Eds.), Work engagement: A handbook of essential theory and research (pp. 102-117). Hove, UK: Psychology Press.

Hartig, T., Mitchell, R., de Vries, S., \& Frumkin, H. (2014). Nature and health. Annual Review of Public Health, 35, 207-228. https://doi.org/10.1146/annurev-publhealth-032013-182443

Jamrozik, A., Clements, N., Hasan, S. S., Zhao, J., Zhang, R., Campanella, C., . . . \& Bauer, B. A. (2019). Access to daylight and view in an office improves cognitive performance and reduces eyestrain: A controlled crossover study. Building and Environment, 165, 106379. https://doi.org/10.1016/j. buildenv.2019.106379

Jenny, G. J., Bauer, G. F., Vinje, H. F., Vogt, K., \& Torp, S. (2017). The application of salutogenesis to work. In M. B. Mittelmark, S. Sagy, M. Eriksson, G. F. Bauer, J. M. Pelikan, B. Lindström, \& G. A. Espnes (Eds.), The handbook of salutogenesis (pp. 197-210). New York: Springer.

Kaarlela-Tuomaala, A., Helenius, R., Keskinen, E., \& Hongisto, V. (2009). Effects of acoustic environment on work in private office rooms and open-plan offices: Longitudinal study during relocation. Ergonomics, 52(11), 1423-1444. https://doi.org/10.1080/00140130903154579

Kaplan, R. (1993). The role of nature in the context of the workplace. Landscape and Urban Planning, 26(1/4), 193-201. https://doi.org/10.1016/0169-2046(93)90016-7

Kaufman, S. B. (2020). Transcend: The new science of self-actualization. New York: TarcherPerigee.

Laurence, G., Fried, Y., \& Slowik, L. (2013). "My space": A moderated mediation model of the effect of architectural and experienced privacy and workspace personalization on emotional exhaustion at work. Journal of Environmental Psychology, 36, 144-152. https://doi.org/10.1016/j.jenvp.2013.07.011

Lesener, T., Gusy, B., \& Wolter, C. (2019). The job demands-resources model: A meta-analytic review of longitudinal studies. Work \& Stress, 33(1), 76-103. https://doi.org/10.1080/02678373.2018.1529065

Lohr, V., Pearson-Mims, C., \& Goodwin, G. (1996). Interior plants may improve worker productivity and reduce stress in a windowless environment. Journal of Environmental Horticulture, 14(2), 97-100. https:// doi.org/10.24266/0738-2898-14.2.97

Mak, C., \& Lui, Y. (2012). The effect of sound on office productivity. Building Services Engineering Research and Technology, 33(3), 339-345. https://doi.org/10.1177\%2F0143624411412253

McNeely, E. (2018). Following footprints: What corporate health can learn from environmental sustain ability. American Journal of Health Promotion, 32(4), 1146-1150. https://doi.org/10.1177/08901171187 65037

Medvedev, O. N., \& Landhuis, C. E. (2018). Exploring constructs of well-being, happiness and quality of life. PeerJ, 6, e4903. https://doi.org/10.7717/peerj.4903

Nieuwenhuis, M., Knight, C., Postmes, T., \& Haslam, S. (2014). The relative benefit of green versus lean offices space: Three field experiments. Journal of Experimental Psychology: Applied, 20(3), $199-214$. https://doi.org/10.1037/xap0000024

Oseland, N., \& Hodsman, P. (2018). A psychoacoustical approach to resolving office noise distraction. Journal of Corporate Real Estate, 20(4), 260-280. https://doi.org/10.1108/JCRE-08-2017-0021

Pejtersen, J., Allermann, L., Kristensen, T., \& Poulsen, O. (2006). Indoor climate, psychosocial work environment and symptoms in open-plan offices. Indoor Air, 16(5), 392-401. https://doi.org/10.1111/j.16000668.2006.00444.x

Raanaas, R., Evensen, K., Rich, D., Sjøstrøm, G., \& Patil, G. (2011). Benefits of indoor plants on attention capacity in an office setting. Journal of Environmental Psychology, 31(1), 99-105. https://doi.org/10.1016/j. jenvp.2010.11.005

Roskams, M., \& Haynes, B. P. (2019). Salutogenic workplace design: A conceptual framework for supporting sense of coherence through environmental resources. Journal of Corporate Real Estate, 22(2), 139-153. https://doi.org/10.1108/JCRE-01-2019-0001

Roskams, M., \& Haynes, B. P. (2020). Testing the relationship between objective indoor environment quality and subjective experiences of comfort. Building Research $\mathcal{E}$ Information. Advance online publication. https://doi.org/10.1080/09613218.2020.1775065

Roskams, M., \& Haynes, B. P. (2021). Environmental demands and resources: A framework for understanding the physical environment for work. Facilities, ahead-of-print.

Rupp, R., Vásquez, N., \& Lamberts, R. (2015). A review of human thermal comfort in the built environment. Energy and Buildings, 105, 178-205. https://doi.org/10.1016/j.enbuild.2015.07.047 
Sander, E., Caza, A., \& Jordan, P. (2018). Psychological perceptions matter: Developing the reactions to the physical work environment scale. Building and Environment, 148, 338-347. https://doi.org/10.1016/j. buildenv.2018.11.020

Satish, U., Mendell, M., Skekhar, K., Hotchi, T., Sullivan, D., Steufert, S., \& Fisk, W. (2012). Is CO2 an indoor pollutant? Direct effects of low-to-moderate CO2 concentrations on human decision-making performance. Environmental Health Perspectives, 120(12), 1671-1677. https://doi.org/10.1289\%2Fehp.1104789

Schaufeli, W. B., \& Taris, T. W. (2014). A critical review of job demands-resources model. Implications for improving work and health. In G. Bauer \& O. Hammig (Eds.), Bridging occupational, organizational and public health (pp. 43-68). New York: Springer.

Seppänen, O., Fisk, W., \& Mendell, M. (1999). Association of ventilation rates and CO2 concentrations with health and other responses in commercial and institutional buildings. Indoor Air, 9(4), $226-252$. https://doi.org/10.1111/j.1600-0668.1999.00003.x

Serafeim, G., Rischbeith, A., \& Koh, H. (2020). Sustainability, business, and health. Journal of the American Medical Association, 324(2), 147-148. https://doi.org/10.1001/jama.2020.8714

Smith, A., \& Pitt, M. (2009). Sustainable workplaces: Improving staff health and well-being using plants. Journal of Corporate Real Estate, 11(1), 52-63. https://doi.org/10.1108/14630010910940552

Sundstrom, E., Burt, R., \& Kamp, D. (1980). Privacy at work: Architectural correlates of job satisfaction and job performance. The Academy of Management Journal, 23(1), 101-117. https://doi.org/10.5465/255498

Tsai, D., Lin, J., \& Chan, C. (2012). Office workers' sick building syndrome and indoor carbon dioxide concentrations. Journal of Occupational and Environmental Hygiene, 9(5), 345-351. https://doi.org/10.10 $80 / 15459624.2012 .675291$

VanderWeele, T. J. (2017). On the promotion of human flourishing. Proceedings of the National Academy of Sciences of the United States of America, 114(31), 8148-8156. https://doi.org/10.1073/pnas.1702996114

VanderWeele, T. J., McNeely, E., \& Koh, H. (2019). Reimagining health-flourishing. Journal of the American Medical Association, 321(17), 1667-1668. https://doi.org/10.1001/jama.2019.3035

Wahl, D. (2016). Designing a regenerative culture. Bridport, UK: Triarchy Press.

Wells, M., \& Thelen, L. (2002). What does your workspace say about you? The influence of personality, status, and workspace on personalization. Environment and Behavior, 34(3), 300-321. https://doi.org/1 0.1177\%2F0013916502034003002

Wessels, C., Schippers, M., Stegmann, S., Bakker, A., van Baalen, P., \& Proper, K. (2019). Fostering flexibility in the new world of work: A model of time-spatial job crafting. Frontiers in Psychology, 10(505). https://doi.org/10.3389/fpsyg.2019.00505

Weziak-Bialowolska, D., Bialowolski, P., \& McNeely, E. (2019c). Worker's well-being: Evidence from the apparel industry in Mexico. Intelligent Buildings International, 11(3-4), 158-177. https://doi.org/10.108 0/17508975.2019.1618785

Weziak-Bialowolska, D., Bialowolski, P., Leon, C., Koosed, T., \& McNeely, E. (2020c). Psychological climate for caring and work outcomes: A virtuous cycle. International Journal of Environmental Research and Public Health, 17, 7035. https://doi.org/10.3390/ijerph17197035

Weziak-Bialowolska, D., Bialowolski, P., \& McNeely, E. (2020a). The impact of workplace harassment and domestic violence on work outcomes in the developing world. World Development, 126(C), 1-12. https://doi.org/10.1016/j.worlddev.2019.104732

Weziak-Bialowolska, D., Bialowolski, P., Sacco, P. L., VanderWeele, T. J., \& McNeely, E. (2020b). Wellbeing in life and well-being at work: Which comes first? Evidence from a longitudinal study. Frontiers in Public Health, 8, 103. https://doi.org/10.3389/fpsyg.2019.00505

Weziak-Bialowolska, D., Dong, Z., \& McNeely, E. (2018). Turning the mirror on the architects: A study of the open-plan office and work behaviors at an architectural company. Frontiers in Psychology, 9, 2178. https://doi.org/10.3389/fpsyg.2018.02178

Weziak-Bialowolska, D., Koosed, T., Leon, C., \& McNeely, E. (2017). A new approach to the well-being of factory workers in global supply chains: Evidence from apparel factories in Mexico, Sri Lanka, China and Cambodia. In OECD, HEC Paris, \& SnO centre (Eds.), Measuring the impacts of business on well-being and sustainability (pp. 130-154). Paris: OECD and HEC Paris/SnO centre.

Weziak-Bialowolska, D., McNeely, E., \& VanderWeele, T. J. (2019a). Human flourishing in cross cultural settings: Evidence from the US, China, Sri Lanka, Cambodia and Mexico. Frontiers in Psychology, 10, 1269. https://doi.org/10.3389/fpsyg.2019.01269

Weziak-Bialowolska, D., McNeely, E., \& VanderWeele, T. J. (2019b). Flourish index and secure flourish index: Validation in workplace settings. Cogent Psychology, 6, 1. https://doi.org/10.1080/23311908.2019. 1598926 
Wrzesniewski, A., \& Dutton, J. E. (2001). Crafting a job: Revisioning employees as active crafters of their work. Academy of Management Review, 26, 179-201. https://doi.org/10.5465/amr.2001.4378011

Wyon, D., \& Wargocki, P. (2006). Room temperature effects on office work. In D. Clements-Croome (Ed.), Creating the productive workplace (pp. 181-192). Milton, UK: Taylor \& Francis.

Xanthopoulou, D., Bakker, A. B., Demerouti, E., \& Schaufeli, W. B. (2007). The role of personal resources in the job demands-resources model. International Journal of Stress Management, 14, 121-141. https://doi. org/10.1037/1072-5245.14.2.121

Zhang, X., Wargocki, P., Lian, Z., \& Thyregod, C. (2016). Effects of exposure to carbon dioxide and bioeffluents on perceived air quality, self-assessed acute health symptoms, and cognitive performance. Indoor Air, 27, 47-64. https://doi.org/10.1111/ina.12284 